\title{
Management of Acute Trans Scaphoid Peri-Lunate Fracture Dislocation by Closed Reduction and Percutaneous Fixation
}

\author{
Waleed Nafea MD $^{1}$, Ahmed M El-Naggar ${ }^{2}$ \\ Lecturer of orthopedic surgery, Zagazig University, Egypt \\ yousufmmkh@gmail.com
}

Abstract:

Background: Perilunate fracture dislocations (PLFD) are high-energy injuries, produced by wrist hyperextension. Isolated Perilunate dislocations are rare and can be missed.

Patients and methods: 20 patients ( 15 males, 5 females) suffered from traumatic trans-scaphoid perilunate fracture dislocation, all cases were palmar dislocation. Right wrists were injured in 14 patients and left wrists in 6 patients. The mean age of the patients at the time of injury was 33 years (range 19 to 45). The fracture scaphoid was fixed using Herbert screw in 16 cases, and K-wires in 4 patients. Clinical function was evaluated by the Cooney clinical scoring system. Plain X-ray was done for all patients preoperative, direct postoperative, and every visit until the end of follow up period. The radiological outcome included the revised carpal height ratio, radio-lunate angle (RL), scapholunate angle (SL), and presence or absence of midcarpal arthritis.

Results: The average follow-up period was 20 months (range 18-30). Clinically, according to the clinical scoring system described by Cooney, there were 6 (30\%) patients with excellent results, 10 (50\%) good, and 4 (20\%) fair and no poor results were recorded during follow up period. Radiologically, the scaphoid fracture was united in all cases with no evidence of avascular necrosis. The average SL and RL angles in the early postoperative period were 46.5 and -6.0 degrees, respectively. At the last follow-up, average SL and RL angles were 52 and 4.5 degrees, respectively which is significant (p: 0.002). Revised carpal height ratio was 1.53 at the last follow-up.

Conclusion: Closed reduction and percutaneous fixation of scaphoid fracture is considered an effective method for management of acute trans-scaphoid perilunate fracture dislocation provided that accurate anatomic reduction of carpal bones is achieved.

Keywords: trans-scaphoid, fracture, dislocation, scaphoid, fixation INTRODUCTION

The stability of the wrist during motion and interrelated motions depends on the capsuloligamentous integrity and the contact surface contours of the carpal bones [1]. Perilunate fracture dislocations (PLFD) are high-energy injuries, produced by wrist hyperextension. It can be palmar or dorsal. Palmar dislocation is extremely rare and result from a fall on the dorsum of the flexed wrist. This is directly opposite to the mechanism that produces dorsal dislocation [2]

Isolated perilunate dislocations are rare. Lesser arc injuries as described by Johnson are purely ligamentous while greater arc injuries involve a fracture of one or more the bones surrounding the lunate. About $60 \%$ of all perilunate dislocations manifest with a displaced scaphoid fracture, usually in the middle third. Most often, the proximal fragment remains connected to the lunate [3].The exceptions are rare instances in which there is a concomitant scapholunate dissociation, with the proximal fragment being extruded dorsally [4].The ideal goal of treatment is to restore normal anatomy and function as far as possible. Prompt diagnosis and early treatment 
are most important for success. Trans-scaphoid perilunate fracture dislocations can be managed by different methods. Early reduction by closed manipulation is best provided that accurate anatomic reduction is achieved. When accurate reduction is not obtained, open reduction and internal fixation is indicated [5].

Closed manipulation has the advantage of preservation of blood supply to the carpal bones with lower risk of avascular necrosis. Open reduction has the advantage of repair of torn ligaments, removal of interposed soft tissues and removal or fixation of chondral fragments if present [6]. There are several surgical approaches for open reduction of trans-scaphoid perilunate fracture dislocation: the volar or dorsal approach or the combined approach [7].

The aim of this study was to report the results of the treatment of twenty cases with acute trans-scaphoid perilunate fracture dislocation by closed reduction and percutaneous fixation of scaphoid fracture.

\section{PATIENTS AND METHODS}

From August 2009 to December 2014, 20 patients (15 males, 5 females) suffered from acute traumatic trans-scaphoid perilunate fracture dislocation, all cases were palmar dislocation. Right wrists were injured in 14 patients and left wrists in 6 patients. The mean age of the patients at the time of injury was 33 years (range 19 to 45). The mechanism of injury in all patients was forced extension, either due to road traffic accidents in 12 cases or falls from a height in 8 cases. The diagnosis of cases was within a mean time of 48 hours (24-36 hours after injury), and the cases diagnosed more than 7 days from injury were excluded from this study.

\section{Surgical Technique}

In all patients, closed reduction under IV sedation was done in the emergency room by applying longitudinal traction in dorsiflexion followed by palmar flexion, then temporary below elbow cast was applied (Figure 1). The average time elapsed from time of diagnosis to operation was 4 days (2-6 days). The fracture scaphoidwas assessed and reduced using fluoroscopy and fixed using Herbert screw in 16 cases from distal to proximal direction through about $0.5 \mathrm{~cm}$ incision over trapezioscaphoid joint ( Figure 2), and K-wires in 4 patients (Figure 1). During the operation, the reduction of the dislocation was assessed using intraoperative radiology after scaphoid fracture fixation. Below elbow cast was applied for 6 weeks followed by wrist brace for another 6 weeks.

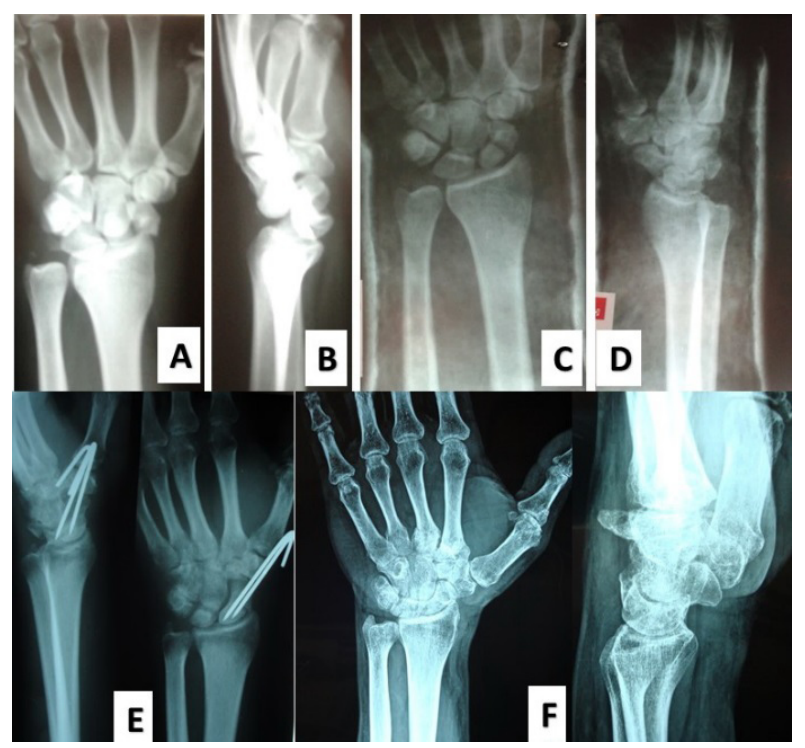

Fig1. male patient 34 years old with traumatic trans-scaphoid perilunar dislocation: A\& B) Preoperative $x$-ray AP and lateral views; $C \& D$ ) $x$-ray after closed reduction of dislocation in cast; E) 2 months postoperative $x$-ray with $k$-wire fixation of scaphoid; F) 30 months postoperative $x$-ray after union and $k$-wire extraction. 


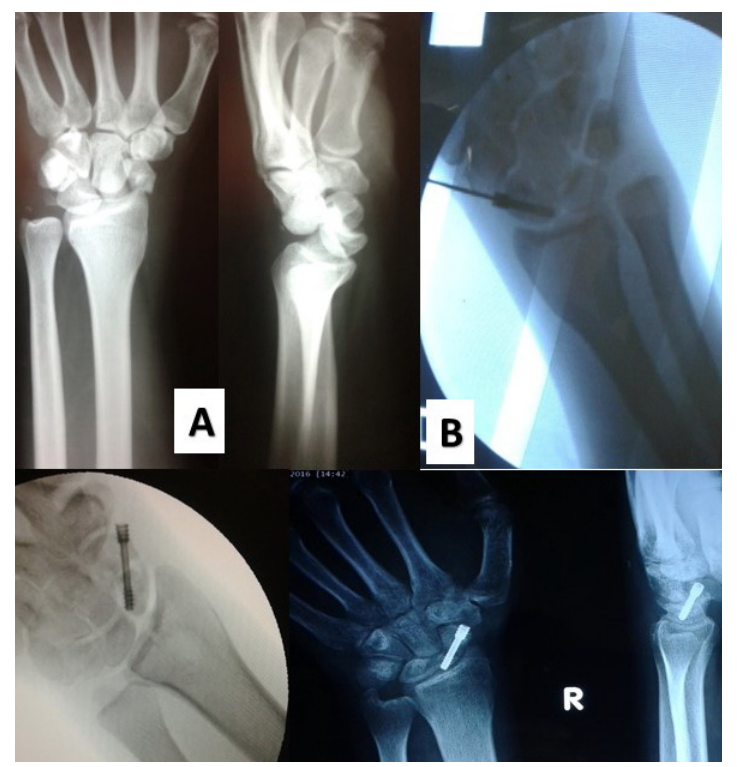

Fig2. male patient 30 years old with traumatic trans-scaphoid perilunar dislocation: A) preoperative x-ray; B) intraoperative radiology with guide wire inside the bone; $C$ ) intraoperative $x$-ray after Herbert screw application and examination of stability; D) $x$-ray 15 months postoperative.

Movements in active and passive forms were allowed after removal of the cast, but weight bearing and manual working were not allowed until complete radiological union and good range of movements without pain. Clinical function was evaluated by the Cooney et al clinical scoring system (Table 1) [8].Plain X-ray was done for all patients preoperative, direct postoperative, and every visit until the end of follow up period. The radiological outcome included the revised carpal height ratio, radio-lunate angle (RL), scapholunate angle (SL), and presence or absence of midcarpal arthritis.

Table1. Green and O'Brien Score (Cooney et al modification) [10]

\begin{tabular}{|c|c|c|}
\hline \multicolumn{3}{|c|}{ I. $\quad$ Pain ( 25 points $)$} \\
\hline & $\circ \quad 25$ & None \\
\hline & 20 & Mild, occasional \\
\hline & 15 & Moderate, tolerable \\
\hline & $\circ \quad 0$ & Severe or intolerable \\
\hline \multirow[t]{6}{*}{ II. } & Range of $n$ & notion ( 25 points): flexion + extension, percentage of normal \\
\hline & $\circ \quad 25$ & 100 \\
\hline & 15 & $75-99$ \\
\hline & 10 & $50-74$ \\
\hline & 5 & $25-49$ \\
\hline & 0 & $0-24$ \\
\hline \multicolumn{3}{|c|}{ III. Grip strength (25 points), percentage of normal } \\
\hline & $\circ \quad 25$ & 100 \\
\hline & 15 & $75-99$ \\
\hline & 10 & $50-74$ \\
\hline & $\circ \quad 5$ & $25-49$ \\
\hline & 0 & $0-24$ \\
\hline
\end{tabular}

Volume 1 
American Research Journal of Orthopedics and Traumatology (ARJOT)

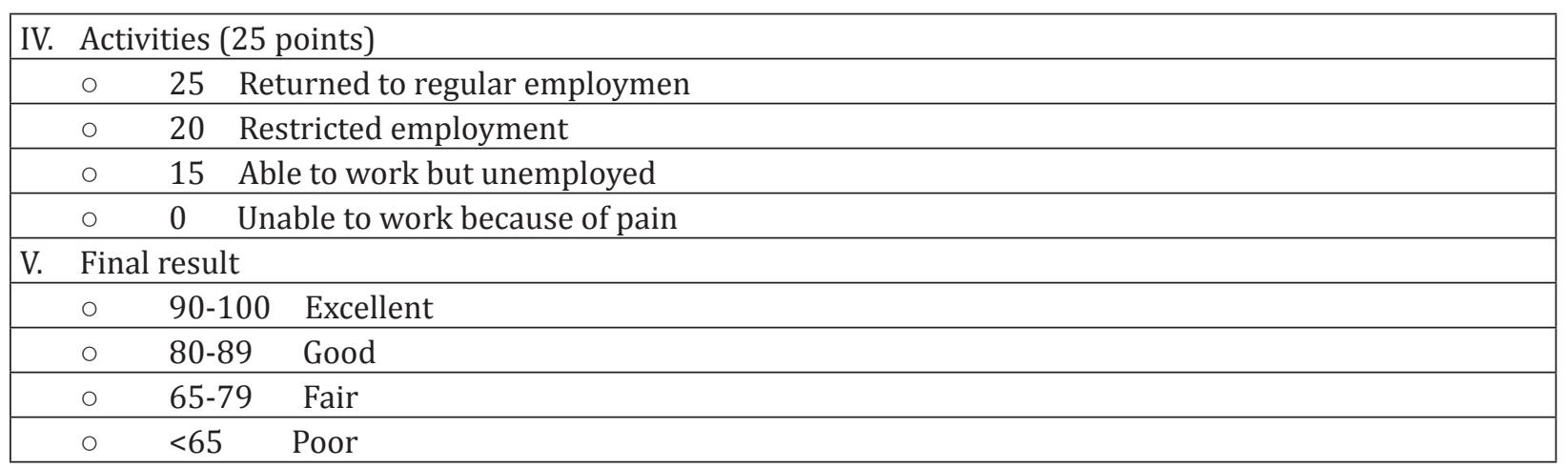

\section{RESULTS}

The average follow-up period was 20 months (range 18 -30). Clinically, according to the clinical scoring system described by Cooney, there were 6 (30\%) patients with excellent results, 10 (50\%) good, 4(20\%) fair and no poor results were recorded during follow up period. The mean postoperative Cooney score was 81 (72-94). 17 patients returned to previous work (85\%)in a mean time of 10 months (8-12). three patients (15\%) who were manual workers had changed their work due to moderate pain with activity. At the end of follow up, the grip power of the hand was measured and it was compared to the other side and no significant difference was found $(\mathrm{P} \geq 0.05)$.

Radiologically, the scaphoid fracture was united in all cases with no evidence of avascular necrosis. The revised carpal height ratio, Radio Lunate angle (RL), Scapho-Lunate angle (SL), and presence or absence of midcarpal arthritis. The average SL and RL angles in the early postoperative period were 46.5 and -6.0 degrees, respectively. At the last follow-up, average SL and RL angles were 52 and 4.5 degrees, respectively which is significant (p: 0.002). Revised carpal height ratio was 1.53 at the last follow-up.

\section{DISCUSSION}

Trans-scaphoid perilunate fracture dislocation is a complex wrist injury that disrupts normal carpal anatomy and wrist biomechanics. These injuries can be managed by different methods either closed reduction and percutaneous fixation or open reduction, ligament repair and internal fixation using either dorsal or volar approach or a combination of both [9-11]. Regardless the method of treatment, timing of surgery is important factor in prognosis. The ideal goal of treatment is to restore normal anatomy and function as soon as possible [12-14]. Herzberg et al showed in their study of 166 perilunate dislocations and fracture dislocations that despite satisfactory clinical outcomes , 56\% of patients treated surgically had radiographic evidence of arthritis. The best results were seen in patients treated early, and a delay in diagnosis was shown to have an adverse effect on the outcome $[7,8]$.

Closed methods have the advantage of preservation of the blood supply to the carpal bones with lower risk of avascular necrosis [6]. Open methods have the advantage of repair of torn ligaments, removal of interposed soft tissues and removal or fixation of chondral fragments $[9,11,12]$.

In this study, there were twenty patients with trans-scaphoid perilunate fracture dislocation managed by closed reduction and percutaneous fixation. There were six excellent results, ten good, four fair, with no poor results. The mean clinical score was 81 (72-94) according to Cooney score. Comparing to other related studies, in the study of Chow, there were eleven cases of trans-scaphoid perilunate fracture dislocation managed by open reduction with ligament repair and internal fixation of scaphoid using a combined dorsal and volar approach [15]. 
In the study of Bagheri et al, there were 23 patients suffered from trans-scaphoid perilunate fracture dislocation. Of these 23 patients , 14were managed by open reduction and internal fixation and 9 were managed by closed methods. The mean Mayo score was 88 in the first group managed by ORIF. The mean Mayo score was 71 in the second group managed by closed methods. The authors in this study suggested that among factors that might impair the wrist function after these injuries is carpal instability, scaphoid nonunion and carpal malalignment [16].

In our study, these factors that impair the wrist function were avoided by achieving accurate anatomic reduction of carpal bones and rigid fixation of scaphoid fracture.

\section{CONCLUSION}

Closed reduction and percutaneous fixation of scaphoid fracture is consideredan effective method for management of acute trans-scaphoid perilunate fracture dislocation provided that accurate anatomic reduction of carpal bones is achieved.

\section{REFERENCES}

1. Johnson RP: The acutely injured wrist and its residuals. ClinOrthop (1980) 149:33-44.

2. Mayfield JK, Johnson RP, Kilcoyne RK: Carpal dislocations: pathomechanicsand progressive perilunar instability. J Hand Surg (1980) 5:226-241.

3. Martinage A, Balaguer T, Chignon-Sicard B, Moteil MC, Dreant N, Leberton E. Perilunate dislocations and fracture dislocations of the wrist, a review of 14 cases [in French]. Chir Main. 2008; 27:31-9.

4. Garg B, Goyal T, Kotwal PP. Staged reduction of neglected transscaphoid perilunate fracture dislocation. a report of 16 cases. J Orthop Surg Res. 2012; 7:19.

5. Souer JS, Rutgers M, Andermahr J, Jupiter JB, Ring D. Perilunate fractue-dislocations of the wrist: comparison of temporary screw versus K-wire fixation. J Hand Surg Am. 2007; 32(3):318-25.

6. Wozasek GE, Moser K-D. Percutaneous screw fixation for fractures of the scaphoid. J Bone Joint Surg (1991) Br 73:138-142.

7. Herzberg G, Comtet JJ, Linscheid RL, Amadio PC, Cooney WP, Stalder J. Perilunate dislocations and fracture-dislocations: a multicenter study. J Hand Surg Am. 1993; 18(5): 768-79.

8. Herzberg G, Forissier D. Acute dorsal trans-scaphoid fracture dislocations: medium-term results. J Hand Surg Br. 2002; 27(6):498-502.

9. Knoll VD, Allan C, Trunble TE. Transscaphoid perilunate fracture dislocations: results of screw fixation of the scaphoid one lunotriquetral repair with a dorsal approach. J Hand Surg Am. 2005; 30(6):1145-52.

10. Cooney WP, Bussey R, Dobyns JH, Llinsch RL. Difficult wrist fractures. Perilunate fractue-dislocations of the wrist. ClinOrthopRelat Res. 1987; 214: 136-47.

11. Melone CP Jr, Murphy MS, Raskin KB Perilunate injuries. Repair by dual dorsal and volar approaches. Hand Clin (2000) 16:439-448.

12. Apergis E, Maris J, Theodoratos G, Pavlakis D, Antoniou N. Perilunate dislocations and fracture-dislocations. Closed and early open reduction compared in 28 cases. ActaOrthopScand Suppl. 1997; 275:55-9.

13. Forli A, Courvoisier A, Wimsey S, Corcella D, Moutet F. Perilunate dislocations and transscaphoid perilunate fracture-dislocations: a retrospective study with minimum ten-year follow-up. J Hand Surg Am. 2010; 35:62-8. 
14. Su CJ, Chang MC, Liu Y, Lo WH. Lunate and perilunate dislocation. Zhonghua Yi XueZaZhi. 1996; 58:348-54.

15. Chow YY. Surgical treatment of transscaphoid perilunate dislocation: a personal approach; Hong Kong Journal of Orthopaedic Surgery 2002;6(2):82-85.

16. Bagheri F, Mohhamad H T, Ali B, Seyyed R S, Masoud M, Meysam F C, Maryam A, and Hasan R. Trans-Scaphoid Perilunate Fracture-Dislocation and Isolated Perilunate Dislocations; Surgical Versus Non-Surgical Treatment; Arch Bone Jt Surg. 2013 Dec; 1(2): 74-77.

Citation: Waleed Nafea MD, Ahmed M El-Naggar, "Management of Acute Trans Scaphoid Peri-Lunate Fracture Dislocation by Closed Reduction and Percutaneous Fixation". American Research Journal of Orthopedics and Traumatology (ARJOT) Volume 1, 2016; pp:1-6

Copyright (C) 2016 Waleed Nafea MD, Ahmed M El-Naggar, This is an open access article distributed under the Creative Commons Attribution License, which permits unrestricted use, distribution, and reproduction in any medium, provided the original work is properly cited. 